\title{
PRODUTIVIDADE DO MILHO EM RESPOSTA À INOCULAÇÃO COM Azospirillum brasilense E ADUBAÇÃO NITROGENADA EM CLIMA SUBTROPICAL
}

\author{
MARCOS RENAN BESEN ${ }^{1}$, RICARDO HENRIQUE RIBEIRO ${ }^{2}$, \\ LUIZ VINICIUS FIGUEROA ${ }^{3}$ e JONATAS THIAGO PIVA ${ }^{3}$
}

\author{
'Universidade Estadual de Maringá, marcos.besen@hotmail.com \\ ${ }^{2}$ Universidade Federal do Paraná, kico_ribeiro@hotmail.com \\ ${ }^{3}$ Universidade Federal de Santa Catarina,vinifigueroa1@yahoo.com.br, jonatas.piva@ufsc.br
}

$\overline{\text { Revista Brasileira de Milho e Sorgo, v.18, n.2, p. 257-268, } 2019}$

\begin{abstract}
RESUMO - O Azospirillum é considerado um dos gêneros de bactérias promotores de crescimento de plantas, com potencial de melhorar a eficiência de uso do nitrogênio $(\mathrm{N})$. Objetivou-se avaliar o efeito da inoculação associado a doses de $\mathrm{N}$ sobre componentes biométricos e de rendimento do milho. Os tratamentos foram arranjados no esquema fatorial 2 x 4, sendo: presença ou ausência de inoculação de $A$. brasilense via semente e quatro doses de $\mathrm{N}$ em cobertura $\left(0,75,150\right.$ e $\left.300 \mathrm{~kg} \mathrm{ha}^{-1} \mathrm{de} \mathrm{N}\right)$, delineados em blocos casualizados com parcelas subdivididas. Cultivou-se duas safras de milho (2013/14 e 2014/15). Os dados foram analisados por meio da técnica de análise conjunta, considerando as duas safras. Uso do Azospirillum brasilense aumentou a altura da planta em $8 \%$ em uma das safras. Contudo, houve decréscimo na produtividade em 2013/14. As doses de $\mathrm{N}$ foram favoráveis para incrementar os componentes do rendimento, havendo efeito linear positivo para a produtividade, revelando que à cada $1 \mathrm{~kg} \mathrm{~N} \mathrm{ha}^{-1}$, houve aumento no rendimento de $33,96 \mathrm{~kg} \mathrm{ha}^{-1}$ de grãos. Conclui-se que a adoção da técnica de inoculação com $A$. brasilense não substitui o uso de $\mathrm{N}$ e tampouco permite a redução da dose, nas condições do presente estudo.
\end{abstract}

Palavras-chave: Zea mays L., Plantio direto, Interação microrganismo-planta, Bactéria diazotrófica.

\section{MAIZE PRODUCTIVITY IN RESPONSE TO INOCULATION WITH Azospirillum brasilense AND NITROGEN FERTILIZATION IN SUBTROPICAL CLIMATE}

\begin{abstract}
Azospirillum is considered one of the genders of plant growth-promoting bacteria with potential to improve nitrogen $(\mathrm{N})$ use efficiency. The objective was to evaluate the effect of inoculation and $\mathrm{N}$ rates on maize biometric and yield components. Treatments were arranged in the factorial 2 x 4 design, being: presence or absence of A. brasilense inoculation via seeds and four $\mathrm{N}$ rates in topdressing $\left(0,75,150\right.$ and $\left.300 \mathrm{~kg} \mathrm{~N}^{-1}\right)$, using the design of complete randomized blocks in subdivided plots. Two maize growing seasons were cultivated (2013/14 e 2014/15). The data were analyzed using the joint analysis technique, considering the two growing seasons. Azospirillum brasilense application via seeds increased the plant height by $8 \%$ in one of the growing seasons. However, it was a decrease in crop productivity in 2013/14. N rates were favorable increasing yield components, with a positive linear effect for grain yield, revealing that for each $1 \mathrm{~kg} \mathrm{~N} \mathrm{ha}^{-1}$, there was an increase in yield of $33.96 \mathrm{~kg} \mathrm{ha}^{-1}$ of grains. We concluded that the adoption of the inoculation technique with $A$. brasilense does not replace the use of $\mathrm{N}$ nor does it allow reduction in the rate under the conditions of the present study.
\end{abstract}

Keywords: Zea mays L., No-tillage, Microorganism-plant interaction, Diazotrophic bacteria. 
A cultura do milho é de extrema importância para o agronegócio brasileiro, de tal modo que na última safra (2017/18) cerca de 5.082,2 mil ha foram destinados ao cultivo do milho primeira safra, apresentando rendimento médio de $5.295 \mathrm{~kg} \mathrm{ha}^{-1}$ (Acompanhamento da Safra Brasileira [de] Grãos, 2018). Verifica-se uma grande variabilidade no rendimento de grãos entre as regiões produtoras à nível nacional, contudo em sua totalidade o rendimento médio é muito aquém do potencial produtivo da cultura. Logo, há necessidade de técnicas de manejo que propiciem incrementos no rendimento de grãos aliadas ao uso eficiente de fertilizantes e recursos naturais. No que tange ao manejo da fertilidade e nutrição, tem-se o N como o nutriente mais demandado pela cultura do milho (Mota et al., 2015), o que resulta num alto investimento, sendo responsável por grande parte do custo de produção. Nesse sentido, a incorporação do recurso biológico ao manejo do N, apresenta potencial em aumentar a eficiência desse nutriente.

Entre as denominadas bactérias promotoras de crescimento das plantas temos as pertencentes ao gênero Azospirillum. Este gênero inclui um grupo de bactérias diazotróficas, que se associam à rizosfera da planta, podendo caracterizar uma colonização externa, ou associada endofiticamente, pois podem penetrar nos espaços intercelulares das raízes (Van Dommelen \& Vanderleyden, 2007). O uso de Azospirillum apresenta-se como alternativa para redução da dose de $\mathrm{N}$, seja devido a fixação biológica do $\mathrm{N}$ ou maior eficiência de uso em virtude do aumento do sistema radicular (Bashan \& De-Bashan, 2010). Aliado a isso, bactérias do gênero Azospirillum apresentam potencial em estimular o desenvolvimento de plantas por múltiplos mecanismos, incluindo síntese de fito-hormônios, melhoria da nutrição nitrogenada, mitigação de estresse e controle biológico da microbiota patogê- nica (Bashan \& De-Bashan, 2010). O principal hormônio produzido por estirpes de Azospirillum é uma auxina, o ácido 3-indolacético (AIA), responsável por induzir alongamento e divisão celular na planta.

Em estudo realizado por Kappes et al. (2013) observou-se acréscimo de 9,4\% no rendimento de grãos de milho com a inoculação de $A$. brasilense, em Latossolo Vermelho no estado do Mato Grosso do Sul. Cunha et al. (2014) citam que a dose ideal de N em cobertura para o milho inoculado é de aproximadamente $89 \%$ da dose recomendada, pois o efeito positivo de A. brasilense foi afetado no uso de $100 \%$ da dose de N recomendada. Não obstante, Galindo et al. (2017) verificaram que a inoculação com $A$. brasilense tornou o cultivo de milho mais lucrativo, independentemente da dose e fonte de N, sob um Latossolo no Cerrado há 10 anos cultivados sob plantio direto, sendo o maior retorno econômico obtido na dose de $100 \mathrm{~kg} \mathrm{ha}^{-1}$ de $\mathrm{N}$, com ureia convencional associada à inoculação.

Do mesmo modo, Libório et al. (2016) reportaram que a produtividade de grãos com a associação de metade da dose de $\mathrm{N}$ e Azospirillum brasilense foi equivalente ao tratamento que recebeu o total da dose de $\mathrm{N}$ recomendada para a cultura, sob condições de clima tropical. Bem como, Mumbach et al. (2017) verificaram que a redução pela metade da dose de $\mathrm{N}$ em cobertura, associada à inoculação, não afetou o rendimento de milho em condições de clima subtropical no Noroeste do Rio Grande do Sul. Resultados contrários aos obtidos por Pandolfo et al. (2015), que após a realização de dois experimentos, nos municípios de Campos Novos e Papanduva, ambos no estado de Santa Catarina, concluíram que a inoculação de sementes de milho com Azospirillum brasilense não aumenta o rendimento de grãos, massa de mil grãos e demais variáveis relacionadas ao crescimento da planta. Tais resultados evidenciam que a eficiência do 
Azospirillum brasilense é dependente das condições do ambiente, como clima e solo.

Nesse sentido, o presente trabalho foi elaborado com a hipótese de que a inoculação de sementes de milho com A. brasilense incrementa os componentes biométricos e de rendimento do milho, possibilitando a redução da dose de $\mathrm{N}$ mineral aplicada em cobertura. Assim, o objetivo foi avaliar o efeito da inoculação com $A$. brasilense, via semente, associada à doses de nitrogênio na cultura do milho sob condições de clima subtropical, em solo de alta fertilidade.

\section{Material e Métodos}

O trabalho foi realizado na fazenda experimental da UFSC Campus Curitibanos, em dois anos agrícolas, safras 2013/2014 e 2014/2015. A área está situada à uma latitude $27^{\circ} 16^{\prime} 26.55^{\prime}$ ' sul e longitude de 50³0'14.41" oeste, com altitude de 1000 metros. $\mathrm{O}$ clima da região é classificado como $\mathrm{Cfb}$ subtropical com temperatura média entre $15^{\circ} \mathrm{C}$ e $25^{\circ} \mathrm{C}$, com uma precipitação média anual de $1600 \mathrm{~mm}$. Os dados de precipitação e temperatura média diária durante o período do experimento são apresentados na Figura 1.

O solo da área experimental é classificado como CAMBISSOLO HÁPLICO típico de textura argilosa (Santos et al., 2013), com $550 \mathrm{~g} \mathrm{~kg}^{-1}$ de argila na camada superficial. Antes da implantação do experimento, o solo apresentou as seguintes características químicas na profundidade de 0,00-0,20 m: 36,19 $\mathrm{g} \mathrm{dm}^{-3}$ de matéria orgânica; $10,70 \mathrm{mg} \mathrm{dm}^{-3}$ de fósforo; $0,10 \mathrm{cmol}_{\mathrm{c}} \mathrm{dm}^{-3}$ de potássio; $\mathrm{pH}\left(\mathrm{em}^{\mathrm{CaCl}}{ }_{2}\right)$ de 6,00 . Essa área vinha sendo utilizada nos anos anteriores com culturas de grãos, em sistema de plantio direto.

Foi utilizado o delineamento experimental de blocos completos ao acaso em esquema fatorial $2 \times 4$ arranjados em parcelas subdivididas com quatro repetições. As parcelas principais foram alocadas com e sem o uso de inoculante e possuíram dimensões de $64 \mathrm{~m}^{2}(16 \mathrm{~m} \times 4 \mathrm{~m})$. Nas subparcelas, com $16 \mathrm{~m}^{2}(4 \mathrm{~m}$ $\mathrm{x} 4 \mathrm{~m}$ ) foram aplicadas as doses de nitrogênio em cobertura $\left(0,75,150\right.$ e $300 \mathrm{~kg} \mathrm{ha}^{-1}$ de $\left.\mathrm{N}\right)$, sendo utilizado a ureia como fonte $(45 \%$ de $\mathrm{N})$. A inoculação das sementes foi realizada utilizando o $A$. brasilense da marca AZOTOTAL ${ }^{\circledR}\left(2.0 \times 10^{8} \mathrm{UFC} \mathrm{mL}^{-1}\right)$ na dose de $125 \mathrm{~mL}$ do inoculante à cada $20 \mathrm{~kg}$ de sementes. As
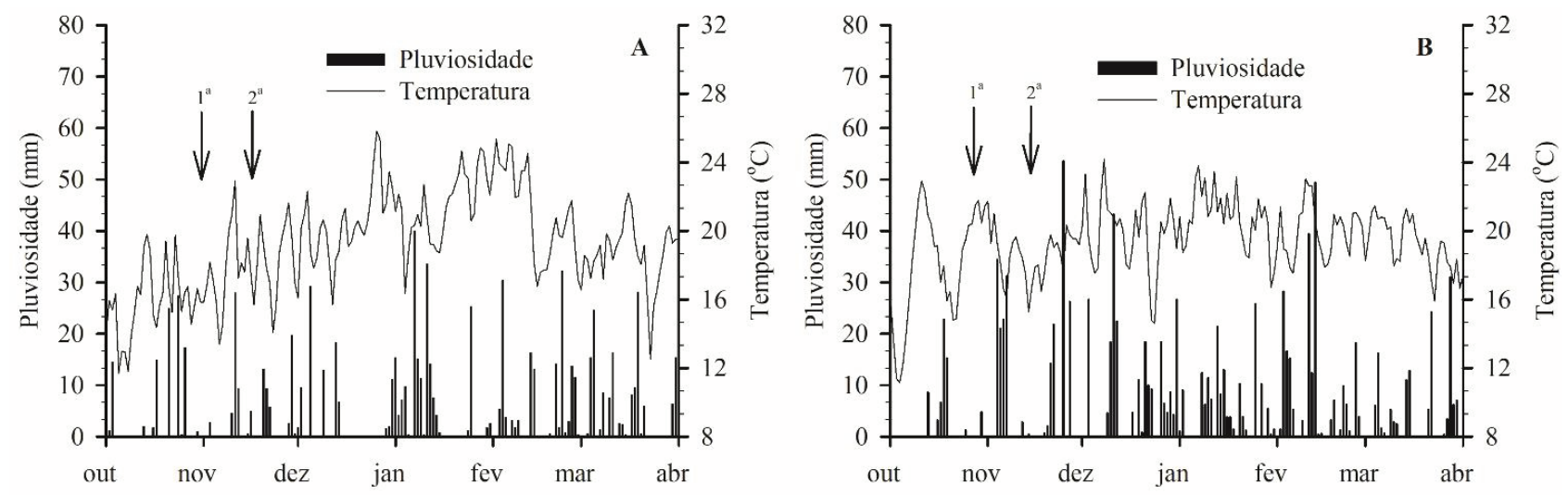

Figura 1. Pluviosidade $(\mathrm{mm})$ e temperatura média do $\operatorname{ar}\left({ }^{\circ} \mathrm{C}\right)$, durante os períodos de condução do experimento: 2013/14 (A) e 2014/2015(B). As setas indicam as épocas de aplicação do nitrogênio. Curitibanos, SC. Fonte: Inmet. 
doses de $\mathrm{N}$ foram aplicadas a lanço de forma parcelada em duas etapas, sendo a primeira na emergência da cultura e a segunda no estádio V4.

A semeadura do milho foi realizada sob palhada de aveia (Avena strigosa), utilizando uma semeadora adubadora num espaçamento de $0,70 \mathrm{~m}$ entre fileiras. Foi realizada na primeira quinzena do mês de outubro de cada ano, de acordo com o zoneamento de risco climático para a região. Nas duas ocasiões utilizou-se o hibrido SYN7205, adaptado para a região, buscando uma densidade de 65 mil plantas $\mathrm{ha}^{-1}$. Os tratos culturais e o manejo fitossanitário seguiram as recomendações técnicas da cultura. Na semeadura do milho, nos dois anos, foram utilizados $400 \mathrm{~kg} \mathrm{ha}^{-1}$ do adubo formulado 00-20-20 (N-P-K).

As avaliações realizadas na cultura do milho no período de pleno florescimento foram as seguintes: diâmetro do colmo, altura da planta, altura de inserção da primeira espiga. A altura da planta foi medida desde a superfície do solo até a bainha da folha bandeira com a utilização de uma trena $(\mathrm{m})$. O diâmetro do colmo foi determinado a $20 \mathrm{~cm}$ de altura do solo, com o uso de um paquímetro digital ( $\mathrm{mm}$ ) e a altura de inserção da espiga principal foi avaliada desde a superfície do solo até a inserção da espiga, com utilização de uma trena.

Os componentes de produção, comprimento da espiga, número de grãos por fileira, número de fileiras por espiga, massa de mil grãos, produtividade de grãos $\left(\mathrm{kg} \mathrm{ha}^{-1}\right)$, foram avaliados no estádio de maturação fisiológica das plantas (R6). Para estas medidas utilizou-se 10 espigas coletadas ao acaso por parcela. A produtividade e a massa de mil grãos tiveram a umidade corrigida a $14 \%$.

Inicialmente os dados foram verificados quanto a normalidade dos erros pelo teste de Shapiro-Wilk e posteriormente submetidos a análise de variância individual afim de verificar a possibilidade de análise conjunta, adotando como critério a razão entre os quadrados médios residuais de 7:1 conforme proposto por Banzato \& Kronka (2015). Assim, foi possível a realização da técnica de análise conjunta para todas as variáveis. Na presença de interações significativas, procederam-se os desdobramentos necessários $(p<0,10)$. Para os fatores ano e inoculação com apenas 1 grau de liberdade o $\mathrm{F}$ foi conclusivo $(p<0,05)$. Para as doses de $\mathrm{N}$ efetuou-se análise de regressão, sendo verificada a significância dos betas pelo teste $T$. Efetuou-se também análise de correlação de Pearson entre as variáveis respostas.

\section{Resultados e Discussão}

Não houve interação de segundo grau para nenhuma das variáveis analisadas. No entanto, interações de primeiro grau entre doses de $\mathrm{N}$ e ano foram observadas para as variáveis diâmetro do colmo, número de fileiras por espiga, grãos por fileira, massa de mil grãos e comprimento da espiga. Houve também interação entre ano e inoculação para altura da planta e produtividade (Tabela 1).

O desdobramento da interação entre inoculante e ano, revelou aumento de $8 \%$ na altura de plantas na safra 2014/15 com a inoculação. Por sua vez, a altura de inserção da espiga foi influenciada somente pelo ano, sendo observados maiores valores na safra 2014/15 (Tabela 2). Já as maiores produtividades foram observadas na ausência da inoculação no cultivo realizado em 2013/14, enquanto na safra seguinte não houve efeito significativo do $A$. brasilense. Possivelmente, a maior produtividade obtida em 2014/15 se deve à melhores condições ambientais, à citar, maior regime pluviométrico no início do desenvolvimento da cultura (Figura 1). 
Tabela 1. Resumo da análise de variância por meio da análise conjunta com os respectivos graus de liberdade (Gl) e quadrados médios das seguintes variáveis: diâmetro do colmo (DC), altura de planta (AP), altura de inserção da espiga (AIE), número de fileiras por espiga (FE), grãos por fileira (GF), comprimento da espiga (CE), massa de mil grãos (MMG) e produtividade em $\mathrm{kg} \mathrm{ha}^{-1}$ (PROD).

\begin{tabular}{|c|c|c|c|c|c|c|c|c|c|}
\hline \multirow{2}{*}{$\mathrm{FV}^{1}$} & \multirow{2}{*}{ Gl } & \multicolumn{8}{|c|}{ Valores de quadrado médio } \\
\hline & & $\mathrm{DC}$ & AP & AIE & $\mathrm{FE}$ & GF & $\mathrm{CE}$ & MMG & PROD \\
\hline Bloco/Ano & 6 & 9,08 & 0,10 & 0,09 & 0,15 & 13,72 & 1,25 & 600,74 & 1171182,39 \\
\hline Ano & 1 & $68,55^{*}$ & $1,34^{*}$ & $1,30^{*}$ & $44,74 *$ & $377,43 *$ & $0,29^{\mathrm{ns}}$ & $170309,94 *$ & $47479420,9 *$ \\
\hline Inoc & 1 & $19,93^{\mathrm{ns}}$ & $0,06^{\mathrm{ns}}$ & $0,005^{\mathrm{ns}}$ & $0,08^{\mathrm{ns}}$ & $50,80^{\mathrm{ns}}$ & $3,34^{\mathrm{ns}}$ & $300,71^{\mathrm{ns}}$ & $12684950,04 *$ \\
\hline Ano x Inoc & 1 & $4,24^{\mathrm{ns}}$ & $0,28^{*}$ & $0,021^{\text {ns }}$ & $0,18^{\mathrm{ns}}$ & $0,04^{\mathrm{ns}}$ & $0,19^{\mathrm{ns}}$ & $138,15^{\mathrm{ns}}$ & $2737680,47^{*}$ \\
\hline Erro A & 6 & 3,85 & 0,04 & 0,02 & 0,10 & 26,38 & 2,91 & 1254,11 & 674438,22 \\
\hline Nitro & 3 & $102,26^{*}$ & $0,59 *$ & $0,48^{*}$ & $0,66^{\mathrm{ns}}$ & $140,76^{*}$ & $40,16^{*}$ & $31122,64 *$ & $312430565,9 *$ \\
\hline Nitro $x$ Inoc & 3 & $4,05^{\mathrm{ns}}$ & $0,02^{\mathrm{ns}}$ & $0,002^{\text {ns }}$ & $0,08^{\mathrm{ns}}$ & $4,46^{\mathrm{ns}}$ & $0,31^{\mathrm{ns}}$ & $246,89^{\text {ns }}$ & $937969,55^{\text {ns }}$ \\
\hline Nitro x Ano & 3 & $8,32 *$ & $0,008^{\mathrm{ns}}$ & $0,001^{\text {ns }}$ & $1,81^{*}$ & $68,06^{*}$ & $14,84^{*}$ & $11189,40^{*}$ & $1604745,9^{\text {ns }}$ \\
\hline Nitro $x$ Ano x Inoc & 3 & $2,46^{\mathrm{ns}}$ & $0,01^{\mathrm{ns}}$ & $0,013^{\mathrm{ns}}$ & $0,18^{\mathrm{ns}}$ & $12,26^{\mathrm{ns}}$ & $0,63^{\mathrm{ns}}$ & $616,01^{\mathrm{ns}}$ & $4320432,94^{\mathrm{ns}}$ \\
\hline Erro B & 36 & 2,85 & 0,02 & 0,006 & 0,38 & 15,35 & 4,57 & 928,74 & 2921450,65 \\
\hline Total & 63 & & & & & & & & \\
\hline CV $1(\%)$ & & 9,10 & 10,28 & 11,98 & 1,94 & 18,80 & 12,56 & 11,78 & 9,01 \\
\hline CV $2(\%)$ & & 7,83 & 6,65 & 6,62 & 3,76 & 14,34 & 15,73 & 10,14 & 18,76 \\
\hline
\end{tabular}

${ }^{1} \mathrm{FV}=$ fontes de variação, onde Inoc= inoculação com A. brasilense; Nitro= dose de nitrogênio. * significativo a $5 \%$ de probabilidade e ${ }^{\mathrm{n} s}$ não significativo pelo teste $\mathrm{F}$.

Barassi et al. (2008) avaliando trabalhos sobre as respostas fisiológicas induzidas por Azospirillum, relataram maior elasticidade da parede celular, maior produção de biomassa e maior altura de plantas, além de outros benefícios, aumentando as variáveis morfológicas da cultura. No entanto no presente estudo, alterações por exemplo, na altura de plantas em função da inoculação, foram observadas, porém sem conformidade entre os resultados de cada safra. Também não houve efeitos do $A$. brasilense para o diâmetro do colmo, diferentemente do encontrado por Matos et al. (2017), os quais observaram aumento linear sobre essa variável com doses crescentes de $\mathrm{N}$ aliadas à inoculação. Da mesma forma não houve efeito da inoculação com $A$. brasilense para as variáveis de espiga, grãos por fileira, fileiras por espiga e comprimento da espiga. Isso denota que as interações entre adubação nitrogenada e Azospirillum brasilense em plantas de milho, ainda não são claras, principalmente para as condições de clima mais ameno.

Outros trabalhos apontam maior desenvolvimento radicular no milho e demais gramíneas (Nozaki et al., 2013; Kazi et al., 2016) após inoculação com Azospirillum brasilense. O maior desenvolvi- 
Tabela 2. Efeito da inoculação e ano agrícola para as variáveis altura de planta, altura de inserção de espiga e produtividade de grãos da cultura do milho em duas safras agrícolas. Curitibanos, SC.

\begin{tabular}{lll}
\hline & \multicolumn{2}{c}{ Ano agrícola } \\
\hline & $2013 / 14$ & $2014 / 15$ \\
\hline \multicolumn{2}{c}{ Altura da planta (m) } \\
Com inoculante & $1,99 \mathrm{Ab}$ & $2,41 \mathrm{Aa}$ \\
Sem inoculante & $2,06 \mathrm{Aa}$ & $2,22 \mathrm{Ba}$ \\
\hline & Altura de inserção da espiga (m) \\
Com inoculante & $1,06 \mathrm{Ab}$ & $1,38 \mathrm{Aa}$ \\
Sem inoculante & $1,11 \mathrm{Aa}$ & $1,36 \mathrm{Aa}$ \\
\hline
\end{tabular}
Produtividade $\left(\mathrm{kg} \mathrm{ha}^{-1}\right)$

Com inoculante $\quad 7597,18 \mathrm{Bb} \quad 9733,46 \mathrm{Aa}$

Sem inoculante $8901,23 \mathrm{Ab} \quad 10210,21 \mathrm{Aa}$

Letras maiúsculas diferentes na coluna e minúsculas na linha para cada variável diferem entre si pelo teste $\mathrm{F}$ à $5 \%$ de probabilidade.

mento radicular concomitante à exploração mais eficiente dos recursos do sistema solo, tende a refletir em acréscimos na produtividade quando as condições forem adversas (limitações hídrica e nutricional). Desse modo, embora no presente estudo não tenha se avaliado o sistema radicular, uma hipótese levantada consiste em que o maior crescimento radicular, em detrimento da parte aérea pode ter contribuído para os resultados obtidos, dado as condições químicas do solo favoráveis ao pleno desenvolvimento das plantas. Conforme Calzavara et al. (2018), o uso da inoculação de $A$. brasilense no milho, em condições não limitantes de $\mathrm{N}$ no solo, promoveram alterações fisiológicas, como aumento do metabolismo fotossintético e redução na assimilação/absorção de N. Segundo os autores essas alterações não afetaram a biomassa da planta, sugerindo que o carbono e energia produzidos pelo metabolismo da planta foram drenados pelas bactérias associativas.
Nesse sentido, Partida-Martínez e Heil (2011) retratam o conceito de custo-benefício em interações associativas, abordando a hipótese de que incrementos produtivos advindos dessas interações somente poderão ocorrer, caso os microrganismos proporcionem benefícios superiores ao custo metabólico que a planta exerce para a manutenção de elevadas populações microbianas a si associadas. Desse modo, a inoculação de bactérias promotoras do crescimento de plantas com atuação sobre a nutrição da planta, favorecendo a nutrição/assimilação do $\mathrm{N}$, por exemplo, poderá atuar como dreno energético, caso as condições do local de cultivo já sejam favoráveis a planta (Calzavara et al., 2018), como as encontradas no presente estudo.

Em estudo realizado por Lana et al. (2012) a inoculação proporcionou produtividade semelhante àquela obtida com $100 \mathrm{~kg} \mathrm{ha}^{-1}$ de $\mathrm{N}$ em cobertura, na safra 2000/2001, enquanto em safra posterior (2002/2003) em associação com a adubação em cobertura, a inoculação reduziu a produtividade e a biomassa seca de parte aérea. Os autores atribuem esse efeito, à presença de grandes quantidades de amônio no solo, o que reduz ou até inibe a atividade da enzima nitrogenase, a qual é responsável em converter $\mathrm{N}$ atmosférico $\left(\mathrm{N}_{2}\right)$, na bactéria, em formas assimiláveis pelas plantas. Embora seja evidente que os benefícios do Azospirillum são múltiplos e não se restringem apenas a fixação biológica de N (Bashan \& De-Bashan, 2010).

Em estudo realizado por Sangoi et al. (2015) não foram observados ganhos no aspecto produtivo da cultura do milho com a inoculação de $A$. brasilense. Os autores mencionam que o alto teor de matéria orgânica do solo $\left(50,0 \mathrm{~g} \mathrm{~kg}^{-1}\right)$ pode ter aumentado a disponibilidade de $\mathrm{N}$ às plantas, e consequentemente mitigado os benefícios da inoculação. Justificati- 
va também ponderável ao presente estudo, cuja área apresentava teores de $36,19 \mathrm{~g} \mathrm{dm}^{-3}$ de MO.

Em estudo de meta-análise realizado no Brasil, Zeffa et al. (2018) constataram que a inoculação de milho com Azospirillum spp. aumentou a produtividade em $651,58 \mathrm{~kg} \mathrm{ha}^{-1}$ considerando todos os experimentos e em 1034,28 $\mathrm{kg} \mathrm{ha}^{-1}$ considerando apenas os ensaios sem o fornecimento de $\mathrm{N}$ em cobertura. Todavia, o aumento médio de produtividade de 651,58 $\mathrm{kg} \mathrm{ha}^{-1}$ atribuído ao Azospirillum tende a diminuir em $4,36 \mathrm{~kg} \mathrm{ha}^{-1}$ à cada $1 \mathrm{~kg}$ de $\mathrm{N}$ aplicado, indicando que as práticas não são aditivas. Dessa forma, a recomendação dos autores é de não combinar inoculação com adubação nitrogenada, indo de encontro ao observado no presente estudo. Apesar disso, o uso de inoculantes com bactérias do gênero Azospirilum pode ser considerado uma prática promissora, sob condições limitantes de cultivo (Zeffa et al., 2018).

Skonieski et al. (2017) salientam que as respostas variadas encontradas pela interação entre $A$. brasilense e doses de $\mathrm{N}$ ocorrem em função de aspectos relacionados ao solo, tais como textura, matéria orgânica, comunidade bacteriana nativa entre outros fatores, além do regime hídrico após aplicação de N, bem como tipos de híbridos cultivados. Para tal, o aprofundamento de pesquisas na temática abordada é necessário, devendo ainda maximizar o número de variáveis biométricas, nutricionais e fisiológicas, para melhor compreensão do efeito do Azospirillum sobre a cultura do milho.

De maneira geral houve efeito positivo do $\mathrm{N}$ para as variáveis morfológicas, sendo observado ajuste quadrático em função das doses de $\mathrm{N}$, com ponto máximo em 227 e $209 \mathrm{~kg} \mathrm{~N} \mathrm{ha}^{-1}$, para altura da planta e altura de inserção da espiga, respectivamente (Figura 2A, 2B). Ainda, o diâmetro do colmo, apresentou ajuste linear na safra 2014/15, revelando que a cada $\mathrm{kg}$ de $\mathrm{N}$ aplicado houve aumento proporcional à $0,016 \mathrm{~mm}$ e ajuste quadrático na safra 2013/14 (Figura $2 \mathrm{C}$ ). $\mathrm{O}$ aumento no diâmetro do colmo obtido pelas doses de $\mathrm{N}$ é favorável à planta, pois apresenta potencial em reduzir quebras e acamamento (Kappes et al., 2013), aumentando a capacidade da planta em armazenar fotoassimilados que posteriormente contribuirão com o enchimento de grãos.

$\mathrm{O}$ desdobramento dos níveis de $\mathrm{N}$ dentro de cada ano agrícola revelou que na safra 2013/14 as doses de $\mathrm{N}$ aumentaram de modo linear o número de grãos por fileira e comprimento da espiga, porém, sem efeitos para o número de fileiras por espiga. Todavia, na safra 2014/15 ajustou-se o modelo quadrático com ponto de máximo estimado nas doses de 170 , 183 e $200 \mathrm{~kg} \mathrm{~N} \mathrm{ha}^{-1}$, correspondente à 27 grãos por fileira, 18 fileiras por espiga e $15 \mathrm{~cm}$ de comprimento de espiga, respectivamente (Figura 2 D, E e F). Os resultados evidenciam o incremento nesses importantes componentes de rendimento a partir da adubação nitrogenada, da mesma forma que foi observado por Besen et al. (2018), nas mesmas condições de clima e solo do presente estudo. Segundo os autores essas variáveis, juntamente com massa de mil grãos, foram os componentes produtivos que melhor se correlacionaram com a produtividade do milho.

A massa de mil grãos foi influenciada pela interação entre ano e doses de $\mathrm{N}$, sendo que na safra 2013/14 não houve efeito do $N$ apresentando valor médio de 353 g. Contudo, na safra 2014/15 houve aumento linear, variando de 175 à $328 \mathrm{~g}$, para os tratamento sem $\mathrm{N}$ e $300 \mathrm{~kg} \mathrm{~N} \mathrm{ha}^{-1}$, respectivamente (Figura 3A). A variável massa de mil grãos pode ser altamente afetada pelas condições do ambiente, após o florescimento da cultura (Caires \& Milla, 2016), os resultados mostram que no ano com melhor distribuição de chuvas (Figura 1B) houve resposta às doses 

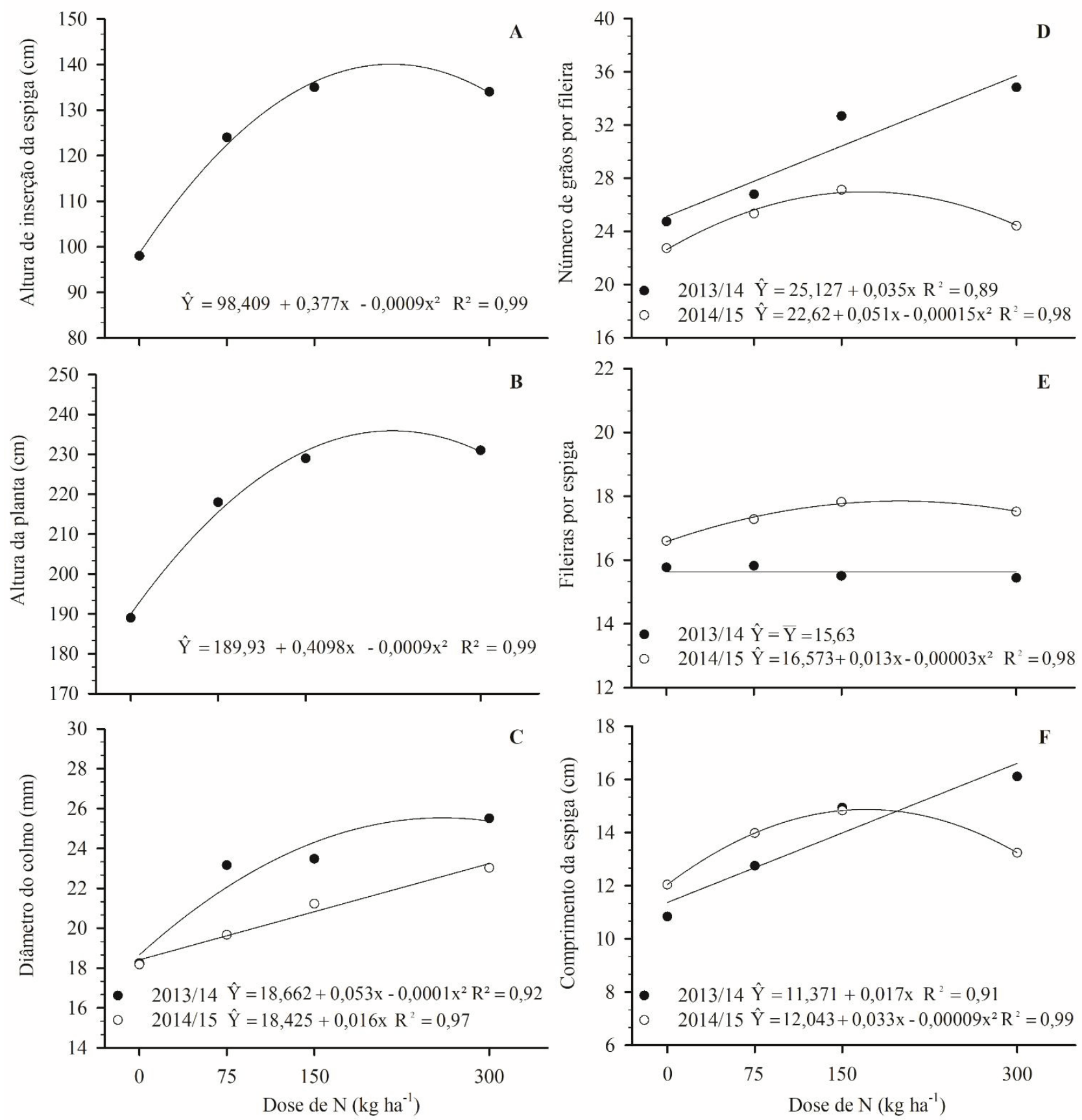

Figura 2. Efeito de doses de N sobre altura de inserção da espiga principal (A), altura da planta (B) e desdobramento dos níveis de $\mathrm{N}$ em cada ano agrícola e sua implicação no diâmetro do colmo (C) número de grãos por fileira (D), número de fileiras por espiga (E) e comprimento da espiga (F) de milho. Média dos tratamentos com e sem inoculação $(n=8)$. Curitibanos, SC. 
de $\mathrm{N}$ aplicadas, denotando o potencial do $\mathrm{N}$ em aumentar esse parâmetro quando em condições climáticas favoráveis. Os autores ressaltam a importância dessa variável para definição da produtividade do milho, corroborando com outros trabalhos (Besen et al., 2018; Mota et al., 2015; Sangoi et al., 2015).

Seguindo o mesmo comportamento das demais variáveis, a produtividade de grãos aumentou linearmente, denotando que na média dos anos, à cada 1 $\mathrm{kg}$ de $\mathrm{N}$ aplicado houve incremento de $34 \mathrm{~kg} \mathrm{ha}^{-1} \mathrm{de}$ grãos, ocasionando uma variação de 4.546 à 14.436 $\mathrm{kg} \mathrm{ha}^{-1}$ no tratamento sem $\mathrm{N}$ e $300 \mathrm{~kg} \mathrm{ha}^{-1}$ de N, respectivamente (Figura 3B). Conforme estudo conduzido por Mota et al. (2015) o aumento positivo em produtividade do milho em função de doses crescentes de $\mathrm{N}$ é relacionado ao aumento do teor de $\mathrm{N}$ e de clorofila na folha, os quais aumentam as taxas fotossintéticas da planta, resultando numa maior produção de grãos por espiga e maior massa de grãos corroborando com o encontrado no presente estudo para essas variáveis. Ainda, o N desempenha funções vitais para a planta, com função estrutural em aminoácidos e proteínas, glico e lipoprotéinas, vitaminas, além de atuar na constituição de todas as enzimas e ativando uma infinidade delas (Malavolta et al., 1997).

Em relação a correlação entre as variáveis, foi possível observar alterações entre os componentes biométricos e de produtividade com o rendimento de grãos em cada ano (Tabela 3 ).

$\mathrm{Na}$ safra 2013/14, as variáveis diâmetro do colmo, altura de inserção da espiga, altura da planta, grãos por fileira e comprimento da espiga correlacionaram-se com o rendimento de grãos, sendo que entre estes o coeficiente de correlação mais expressivo foi entre produtividade e comprimento da espiga $(0,96)$. Resultado semelhante aos encontrados por Besen et al. (2018), para as mesmas variáveis. Já na safra
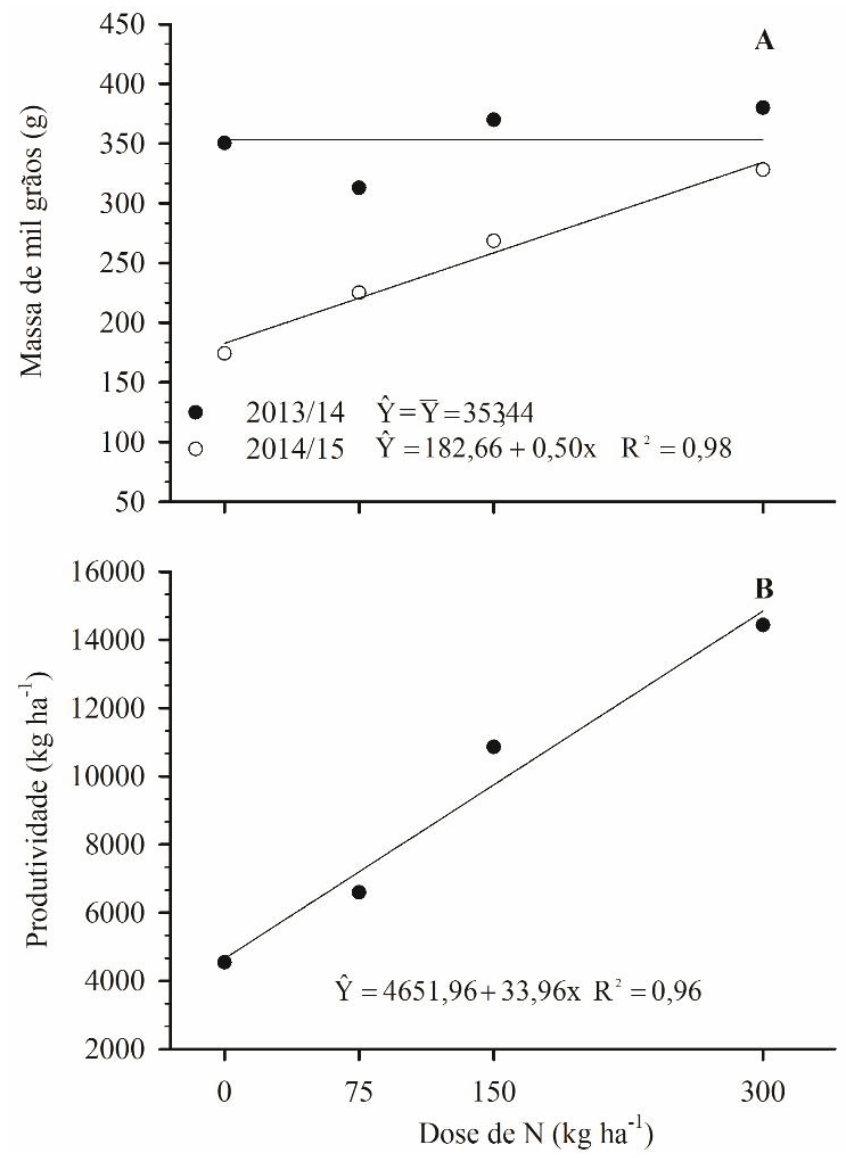

Figura 3. Desdobramento dos níveis de $\mathrm{N}$ em cada ano agrícola para massa de mil grãos (A) e efeito do $\mathrm{N}$ (média das duas safras) para produtividade de grãos (B) da cultura do milho cultivado em clima subtropical. Curitibanos, SC.

2014/15 a produtividade correlacionou-se com diâmetro do colmo, altura de inserção da espiga, número de fileiras por espiga e massa de mil grãos. Nota-se que para este ano, o diâmetro do colmo apresentou alta correlação com a produtividade $(0,93)$, revelando forte associação entre as variáveis. Os resultados obtidos demonstram que a produtividade se correlaciona não somente com componentes do rendimento, mas também com parâmetros relacionados ao seu crescimento, tais como altura de inserção da espiga e diâmetro do colmo. 
Tabela 3. Correlação simples de Pearson entre componentes morfológicos e de rendimento da cultura do milho com a produtividade (PROD) em dois anos agrícolas: diâmetro do colmo (DC); altura de inserção de espiga (AIE); altura de planta (AP); fileiras por espiga (FE); grãos por fileira (GF); grãos por espiga (GE); comprimento de espiga (CE) e massa de mil grãos (MMG). Curitibanos, SC.

\begin{tabular}{lllllllll}
\hline \multicolumn{7}{c}{ Safra 2013/14 } \\
\hline DC & AIE & AP & FE & GF & GE & CE & MMG \\
\hline PROD & $0,84^{* *}$ & $0,85^{* *}$ & $0,89^{* *}$ & $-0,65^{\text {ns }}$ & $0,69^{*}$ & $0,64^{\text {ns }}$ & $0,96^{* *}$ & $0,60^{\text {ns }}$ \\
\hline \multicolumn{7}{c}{ Safra 2014/15 } \\
\hline PROD & $0,93^{* *}$ & $0,86^{* *}$ & $0,63^{\text {ns }}$ & $0,75^{*}$ & $0,38^{\text {ns }}$ & $0,49^{\text {ns }}$ & $0,40^{\text {ns }}$ & $0,98^{* *}$ \\
\hline
\end{tabular}

${ }^{\text {ns }}$ não significativo $* \mathrm{e}^{* *}$ significativo a 5 e $1 \%$, respectivamente.

A hipótese inicial desse trabalho consistia em que o uso de bactérias diazotróficas poderia aumentar a eficiência de uso do $\mathrm{N}$, contribuindo para elevar o potencial produtivo do milho, em associação ao fertilizante nitrogenado mineral, contudo não se observou tal efeito. Desse modo, para as condições do presente estudo, exemplificada pela fertilidade alta num solo argiloso, em condições de clima ameno sem restrições hídricas, a inoculação não se mostrou uma prática vantajosa.

\section{Conclusões}

Houve efeito favorável da inoculação apenas para a altura da planta com incremento de $8 \%$.

Maiores produtividades foram obtidas na ausência da inoculação, em uma das safras.

$\mathrm{O}$ uso da $A$. brasilense, não possibilita a redução da dose de $\mathrm{N}$ mineral nas condições de clima e solo do presente estudo.

Houve expressivo efeito das doses de $\mathrm{N}$ sobre os componentes biométricos e de rendimento da cultura do milho, sendo a maior produtividade obtida na dose de $300 \mathrm{~kg} \mathrm{ha}^{-1}$ de $\mathrm{N}$.

\section{Referências}

ACOMPANHAMENTO DA SAFRA BRASILEIRA [DE] GRÃOS: safra 2017/18: décimo levantamento. Brasília, DF: Conab, v. 5, n. 10, jul. 2018. 141 p. Disponível em: $<$ https://www.conab.gov.br/info-agro/safras $>$. Acesso em: 21 jul. 2018.

BANZATO, D. A.; KRONKA, S. N. Experimentação agrícola. 4. ed. Jaboticabal: Funep, 2015. 237 p.

BARASSI, C. A.; SUELDO, R. J.; CREUS, C. M.; CARROZZI, L. E.; CASANOVAS, W. M.; PEREYRA, M. A. Potencialidad de Azospirillum en optimizer el crecimiento vegetal bajo condiciones adversas. In: CASSÁN, F. D.; GARCIA DE SALAMONE, I. (Ed.). Azospirillum sp.: cell physiology, plant interactions and agronomic research in Argentina. Buenos Aires: Asociación Argentina de Microbiologia, 2008. p. 49-59.

BASHAN Y.; DE-BASHAN L, E. How the plant growthpromoting bacterium Azospirillum promotes plant growth: a critical assessment. Advances in Agronomy, Amsterdam, v. 108, p. 77-136, 2010.

DOI: 10.1016/S0065-2113(10)08002-8.

BESEN, M. R.; RIBEIRO, R. H.; MELLO, G. R.; BRATTI, F.; PIVA, J. T. Fontes minerais de nitrogênio na sucessão milho-trigo em sistema de plantio direto. Journal 
of Agronomic Sciences, Umuarama, v. 7, n. 1, p. 87-102, 2018 .

CAIRES, E. F.; MILLA, R. Adubação nitrogenada em cobertura para o cultivo de milho com alto potencial produtivo em sistema de plantio direto de longa duração. Bragantia, Campinas v. 75, n. 1, p. 87-95, 2016.

CALZAVARA, A. K.; PAIVA, P. H.; GABRIEL, L. C.; OLIVEIRA, A. L.; MILANI, K.; OLIVEIRA, H. C.; BIANCHINI, E.; PIMENTA, J. A.; OLIVEIRA, M. C.; DIAS PEREIRA, J.; STOLF MOREIRA, R.; PAPEN, H. Associative bacteria influence maize (Zea mays L.) growth, physiology and root anatomy under different nitrogen levels. Plant Biology, Hoboken, v. 20, n. 5, p. 1-9, 2018. DOI: $10.1111 /$ plb.12841.

CUNHA, F.; SILVA, N.; BASTOS, F.; CARVALHO, J.; MOURA, L.; TEIXEIRA, M.; ROCHA, A.; SOUCHIE, E. Efeito da Azospirillum brasilense na produtividade de milho no sudoeste goiano. Revista Brasileira de Milho e Sorgo, Sete Lagoas, v. 13, p. 261-272, 2014.

DOI: 10.18512/1980-6477/rbms.v13n3p261-272.

GALINDO, F. S.; TEIXEIRA FILHO, M. C. M.; TARSITANO, M. A. A.; BUZETTI, S.; SANTINI, J. M. K.; LUDKIEWICZ, M. G. Z.; CLEITON JOSÉ ALVES, C. J.; ARF, O. Economic analysis of corn inoculated with Azospirillum brasilense associated with nitrogen sources and doses. Semina: Ciências Agrárias, Londrina, v. 38, n. 4, p. 1749-1764, 2017.

DOI: $10.5433 / 1679-0359.2017 v 38 n 4 p 1749$.

KAPPES, C.; ARF, O.; ARF, M. V.; FERREIRA, J. P.; DAL BEM, E. A.; PORTUGAL, J. R.; VILELA, R. G. Inoculação de sementes com bactéria diazotrófica e aplicação de nitrogênio em cobertura e foliar em milho. Semina: Ciências Agrárias, Londrina, v. 34, n. 2, p. 527538, 2013. DOI: 10.5433/1679-0359.2013v34n2p527.

KAZI,N.;DEAKER, R.; WILSONA, N.; MUHAMMADA, $\mathrm{K}$.; TRETHOWAN, R. The response of wheat genotypes to inoculation with Azospirillum brasilense in the field. Field Crops Research, Amsterdam, v. 196, p. 368-378, 2016. DOI: 10.1016/j.fcr.2016.07.012.
LANA, M. C.; DARTORA, J.; MARINI, D.; HANN, J. E. Inoculation with Azospirillum, associated with nitrogen fertilization in maize. Revista Ceres, Viçosa, v. 59, n. 3, p. 399-405, 2012.

DOI: 10.1590/S0034-737X2012000300016.

LIBÓRIO, P. H. S.; BÁRBARO-TORNELI, I. M.; NÓBILE, F. O.; ANUNCIAÇÃO, M. G.; MIGUEL, F. B.; SILVA, J. A. A. Inoculação com Azospirillum brasilense associada á adubação nitrogenada reduzida em hibridos de milho. Nucleus, Ituverava, v. 13, n. 2, p. 241-253, 2016. DOI: $10.3738 / 1982.2278 .1559$.

MALAVOLTA, E.; VITTI, G. C.; OLIVEIRA, S. A. Avaliação do estado nutricional das plantas princípios e aplicação. 2. ed. Piracicaba: Potafos, 1997. 319 p.

MATOS, F. B.; OLIVEIRA, F. F.; PIETROSKI, M.; MULLER, P. F.; TAKESHITA, W.; CAIONE, G. Uso de Azospirillum brasilense para o aumento da eficiência da adubação nitrogenada em milho. Revista Brasileira de Milho e Sorgo, Sete Lagoas, v. 16, n. 1, p. 131-141, 2017.

DOI: 10.18512/1980-6477/rbms.v16n1p131-141.

MOTA, M. R.; SANGOI, L.; SCHENATTO, D. E.; GIORDANI, W.; BONIATTI, C. M.; DALL'IGNA, L. Fontes estabilizadas de nitrogênio como alternativa para aumentar o rendimento de grãos e a eficiência de uso do nitrogênio pelo milho. Revista Brasileira de Ciência do Solo, Viçosa, v. 39, n. 2, p. 512-522, 2015.

DOI: 10.1590/01000683rbcs20140308.

MUMBACH, G. L.; KOTOWSKI, I. E.; SCHNEIDER, F. J. A.; MALLMANN, M. S.; BONFADA, E. B.; PORTELA, V. O.; BONFADA, E. B.; KAISER, D. R. Resposta da inoculação com Azospirillum brasilense nas culturas de trigo e de milho safrinha. Revista Scientia Agraria, Curitiba, v.18, n. 2, p. 97-103, 2017.

NOZAKI, M. H.; LORENZATTO, R.; MANCINI, M. Efeito do Azospirillum spp. em associação com diferentes doses de adubação mineral na cultura do trigo. Ensaios e Ciência: Ciências Biológicas, Agrárias e da Saúde, Londrina, v. 17, n. 6, p. 27-35, 2013. 
PANDOLFO, C. M.; VOGT, G. A.; BALBINOT JÚNIOR, A. A.; GALLOTTI, G. C. M.; ZOLDAN, S. R. Desempenho de milho inoculado com Azospirillum brasilense associado a doses de nitrogênio em cobertura. Agropecuária Catarinense, Florianópolis, v. 27, n. 3, p. 94-99, 2015.

PARTIDA-MARTÍNEZ, L. P.; HEIL, M. The microbefree planta: fact or artifact? Frontiers in Plant Science, Lausanne, v. 2, n. 100, p. 1-16, 2011.

DOI: $10.3389 /$ fpls.2011.00100.

SANGOI, L.; SILVA, L. M. M.; MOTA, M. R.; PANISON, F.; SCHMITT, A.; SOUZA, N. M.; GIORDANI, W.; SCHENATTO, D. E. Desempenho agronômico do milho em razão do tratamento de sementes com Azospirillum sp. e da aplicação de doses de nitrogênio mineral. Revista Brasileira de Ciência do Solo, Viçosa, v. 39, n. 4, p. 11411150, 2015.

DOI: 10.1590/01000683rbcs20140736.

SANTOS, H. G. dos; JACOMINE, P. K. T.; ANJOS, L. H. C. dos; OLIVEIRA, V. A. de; LUMBRERAS, J. F.; COELHO, M. R.; ALMEIDA, J. A. de; CUNHA, T. J. F.; OLIVEIRA, J. B. de. Sistema Brasileiro de Classificação de Solos. 3 ed. rev. ampl. Brasília, DF: Embrapa, 2013. $353 \mathrm{p}$.

SKONIESKI，F. R.; VIÉGAS，J.; MARTIN, T. N.; NÖRNBERG, J. L.; MEINERZ, G. R.; TONIN, T. J.; BERNHARD, P.; FRATA, M. T. Effect of seed inoculation with Azospirillum brasilense and nitrogen fertilization rates on maize plant yield and silage quality. Revista Brasileira de Zootecnia, Viçosa, v. 46, n. 9, p. 722-730, 2017. DOI: 10.1590/s1806-92902017000900003.

VAN DOMMELEN,A.; VANDERLEYDEN, J.Associative nitrogen fixation. In: BOTHE, H.; FERGUSON, S. J.; NEWTON, W. E. (Ed.). Biology of the nitrogen cycle. Amsterdam: Elsevier, 2007. p. 179-192.

DOI: 10.1016/B978-044452857-5.50013-8.

ZEFFA, D. M.; FANTIN, L. H.; SANTOS, O. J. A. P.; OLIVEIRA, A. L. M.; CANTERI, M. G.; SCAPIM, C. A.; GONÇALVES, S. A. The influence of topdressing nitrogen on Azospirillum spp. inoculation in maize crops through meta-analysis. Bragantia, Campinas, v. 77, n. 3, p. 493500,2018

DOI: $10.1590 / 1678-4499.2017273$ 